\title{
CONF-8706258--2
}

\section{The Thermodynamics of Pyrochemical Processes \\ for Liquid Mctal Reactor Fuel Cycles}

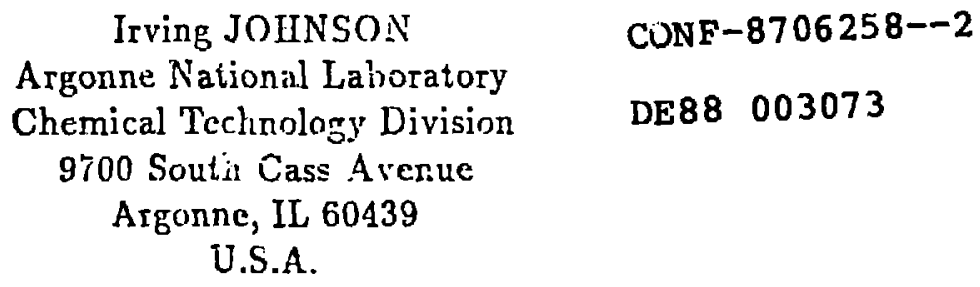

[Abstract] The thermodynamic basis for pyrochemical processes for the recovery and purification of fuel for the liquid metal rractor fuel cycle is described. These processes involve the transport of the uranium and plutonium from one liquid alloy to anothe: through a molten salt. The processes discussed use liquid alioys of cadmium, zinc, and magnesium and moltcn chloide salis. The oxidation-reduction steps are done either chenically by the use of an auxiliary redox couple or electrochenically by the use of an external electrical silpply. The same Easic thermodynamics apply to both the salt transport and the clectrotransport processes. J,arge deviations from ideal solution behavior of the actinides and lanthanides in the liquid alloys have a major influence on the solubilities and the performance of both the salt transport and clectrotransport process:3s. Separation of plutonium and uranium from each other and decontamination fiom the more noble fission product elements can lic achieved using both transport processes. The thermodynamic analysis is used to make process design computations for difierc1,t process conditions.

\section{Introduction}

The development of fast breeder reactors is justified by the greatly increased utilization of uranium . Recent improvement in the pcrformance of metallic fuels ${ }^{1}$ has made feasible a safe and highly efficient reactor if an on-site fuel reprocessing method can be developed. Pyrochemicai processes are ideally suited for the out-of-reactor part of the facl cycie for metallic-fucled fast breeder reactors. Such processes are compact and therefore can be rearily integrated with the reactor ${ }^{2}$. The fuel cycle can be designed so that no fissile materiu! leaves the plant, therefore greatly decreasing the possibility of diversion to use for wcapons.

The overall "chemical" effect of the in-reactor part of the fuel cycle is to convert some of the input plutorium into fission products and some of the uranium into plutonium. Must of the conversion of the plutonium into fission products (fission) occurs in the core region, while mosl of the conversion of uracium to plutonium (breeding) occurs in the blanket region. Therelose, the objective of the out-of-rcactor part of the fuel cycle is to (1) recover the plutonium and uranium from the spent core fuel pins in a form suitable for making new core fuel pins, (2) concentrate the plutonium from the blanket to use for the replacement of the plutoninm fissionei' in the core, and (3) recover the uranium from the blanket in a form suitable for making rew blaniket fuel pins. Removals of fission products must te lerge enough so that the build-up of their in-rcactor inventory does not significantly reduct the performance of the fuel. New uranium (which can be depleted in ${ }^{235} U$ ) to replace that

Work supported by the U.S. Departinent of Energy, Chemical Technology uivision of AivL under Contract î-31-109-Ëng-38.
The wbmitted manuxcript has been authored by a contrector of the U.S. Gowernmen: under contract No, W.31-1002NG-38. Accordingly, the U.S. Government retains a nonexclusive. :oyalty-free license to publish nonexclusive, soyalty-free license to putish
or reproduce the published form of this contribution, or allow orhers to do so, for U. S. Government putposet. 


\section{DISCLAIMER}

This report was prepared as an account of work sponsored by an agency of the United States Government. Neither the United States Government nor any agency thereof, nor any of their employees, makes any warranty, expresr or implied, or assumes any legal liability or responsibility for the accuracy, completeness, or usefulness of any information, apparatus, product, or process disclosed, or represents that its use would not infringe privately owned rights. Reference herein to any specific commercial product, process, or service by trade name, trademark, menufacturer, or otherwise does not necessarily constitute or imply its endorsement, recommendation, or favoring by the United States Government or any agency thereof. The views and opinions of authore expressed herein do not necessarily state or reflect those of the United States Government or any agency thereof. 
conierted to plutonium enters the fuel cycle by being blended with the recovered uranium and is used to prepare new blanket fucl pins. The in-reactor and out-of-reactor parts of the fuel cycle must be balanced to obtain the most efficient reactor.

Pyrochemical processes are compact and readily operated remotely. Because the reagents are highly resistant to radiation damage and opcrate at high temperatures, minimal cooling of the spent fuel is necessary. This reduces the uranium and plutonium inventory and, therefore, the fuel cost. The wastes are dry and concentrated and are readily converted to chemically inert forms. The clicmical scparations and equipment can be designed so thait it is extremely difficult to remove purified plutonium from the fuel cycle, thus reducing the possibility of illegal diversion. This paper describes the thermodynamic basis for the pyrochemical processes for recovering and purifying the fuel in a liquid metal reactor. The basis for design computations are described and illustrated for different process conditions.

\section{Chemical Basis of Processes}

The pyrc shemical processes being considered for metallic-fueled fast reactors involve the dissolution of the metallic fuel in a liquid metal solvent, the oxidation of the uranium and plutonium into a molter salt solvent, the reduction of the uranium and plutonium from the molten salt solution into a liquid metal solvent, and the separation of the metal solvent (by retorting) from the uranium and plutonium. The separations are obtained by control of the conditions during the oxidation and reduction, steps of the process. ${ }^{3}$

The processes to be considered involve the use of molten mixtures of chloride salts and low-melting liquid metals, such as liquid alloys of zinc, cadmium, and magnesium. The early work on these processes was done in connection with the development of a process for the recovery of plutonium and uranium from oxide fast reactor fuels ${ }^{4}$. The first step of thesc processes involved the reduction of the oxide to metal so that the main separations were achieved by molten salt-liquid metal extraction processes ${ }^{5}$.

The oxidation step, $U$ (alloy) $=U^{3+}($ salt $)+3 e^{-}$, requires a sink for the electrons which can be either an electronic conductance path to the second liquid alloy or a reduction reaction, such as $\mathrm{Mg}^{2+}$ (salt) $+2 \mathrm{c}^{-}=M g$ (alloy). Likewise at the second alloy, a source of electrons is required for the reduction reaction, $U^{3+}($ salt $)+3 e^{-}=U$ (allwy), which can be furnished by an external electrical power source or a oxidation reaction. The use of an auxiliary redox couple for the oxidation -reduction steps can be traced to the pioneering work of Chiotti and Parry ${ }^{3}$. It has been extensively developed by Knighton et al. ${ }^{5}$ and is known as the salt transport process. The use of an external power source ${ }^{22}$ for the oxidation-reduction steps was suggested by the success of the electrorefining process for plutonium developed by Mullins and Leary ${ }^{18}$ and various molten salt processes for the electrolytic preparation of high purity uranium ${ }^{23}$ and will be referred to as the electrotransport process. Both processes depend on equilibrium between molten salts and liquid alloys.

\section{Distribution between Molten Salts and Liquid Alloys}

The thermodynamic basis for the separation processes will be developed by calculating the distribution of uranium between a molten chloride salt and liquid magnesium-zinc alloys. 
Table 1

Relative Stabilities of Chlorides at

$1000 \mathrm{~K}$, Values from Pankratz ${ }^{7}$

Values tabulated are $\Delta G f^{\circ} / 2.3 R T$, per g-atom of $\mathrm{Cl}$

$\mathrm{BaCl}_{2}-18.28 \mathrm{MgCl}_{2}-12.68$

$\mathrm{CsCl} \cdot 18.08 \mathrm{UCl}_{3}-11.68$

$\mathrm{KCl}-17.84 \mathrm{ZrCl}_{4}-9.85$

$\mathrm{LiCl}-17.23 \mathrm{ZnCl}_{2}-7.13$

$\mathrm{CaCl}_{2}-16.77 \mathrm{CdCl}_{2}-6.33$

$\mathrm{NaCl}-16.66 \mathrm{CrCl}_{2}-7.09$

$\mathrm{PrCl}_{3}-14.19 \mathrm{FeCl}{ }_{2}-5.73$

$\mathrm{CeCl}_{3}-14.09 \mathrm{NbCl}_{5}-5.42$

$\mathrm{NdCl}_{3}-13.95 \mathrm{NiCl}_{2}-4.09$

$\mathrm{PuCl}_{3}-12.75 \mathrm{MoCl}_{3}-2.81$

The chemical equilibrium is:

$$
U C l_{3}(\text { salt })+\frac{3}{2} M g(\text { alloy })=U(\text { alloy })+\frac{3}{2} \mathrm{MgCl}_{2}(\text { salt })
$$

The equilibrium constant for this reaction can be written as:

$$
\frac{a_{U} a_{M g C l_{2}}^{3 / 2}}{a_{U C l_{3}} a_{M g}^{3 / 2}}=K_{a}
$$

in which the $a$ 's are activities and $K_{a}$ is the activity equilibrium constan t. By substituting for the activities the product of the mole (atom) fractions, $x$, and the activity coefficients, $\gamma$, and defining the distribution coefficient, $D$, of uranium as the ratio $\frac{x_{U C l_{3}}}{x_{U}}$, one obtains the following expression:

$$
\log D=\Delta G^{o} / 2.3 R T-\frac{3}{2} \log a_{M g}+\log \gamma_{U}+\frac{3}{2} \log a_{M g C l_{2}}-\log \gamma_{U C l_{3}}
$$

in which

$$
\Delta G^{\circ}=\frac{3}{2} \Delta G f_{M g C l_{2}}^{o}-\Delta G f_{U C l_{3}}^{o}
$$

It is convenient to separate the right hand side of eq. (3) into three terms ${ }^{6}$. The first term, which depends only on the free energies of formation of the two chlorides, represents the reaction potential. The second two terms, which depend only on the composition of the liquid alloy, represents the reduction potential, while the last two terms, which depend only on the composition of the molten salt phase, represents the oxidation potential. The reaction potential can be considered in terms of the free energies of formation of the chlorides; a short table of numerical values is given in Table 1. 
Table 2

Computation of the Distribution of Uranium

between Molten $\mathrm{MgCl}_{2}$ and Liquid $\mathrm{Zn}-\mathrm{Mg}(1073 \mathrm{~K})$

(see text for references to data)

$\Delta G^{\circ} / 2.3 R T=-3.999$

$\begin{array}{llllll}\mathrm{x}_{M g} & \log D_{O b \mathbf{s}} & \frac{3}{2} \log a_{M g} & \log \gamma_{U} & \log D_{\text {calc }}^{\dagger} & \text { Calc-Obs } \\ 0.0063 & -0.502 & -4.4 .82 & -0.771 & -0.288 & 0.214 \\ 0.0592 & -1.972 & -2.871 & -0.452 & -1.579 & 0.292 \\ 0.1438 & -2.075 & -2.077 & 0.048 & -1.874 & 0.201 \\ 0.2355 & -2.151 & -1.565 & 0.563 & -1.871 & 0.280 \\ 0.2907 & -2.026 & -1.313 & 0.885 & -1.801 & 0.225 \\ 0.4650 & -1.656 & -0.750 & 1.831 & -1.418 & 0.238 \\ 0.6056 & -1.297 & -0.444 & 2.561 & -0.994 & 0.303 \\ 0.6977 & -0.990 & -0.295 & 3.026 & -0.678 & 0.312 \\ 0.7789 & -0.626 & -0.190 & 3.428 & -0.380 & 0.246 \\ 0.8018 & -0.506 & -0.165 & 3.540 & -0.294 & 0.212 \\ & & & & \text { ave: } & 0.252\end{array}$

†Assumes that $\log \gamma_{U C l_{3}}=0$

$\ddagger$ Equal to $\log \gamma \cup \mathrm{Cl}_{\mathrm{s}}$

The entries in Table 1 are the free energies of formation (at $1000 \mathrm{~K}$ ) for one gram atom of chlorine divided by 2.3RT. Differences in Table 1, after correction for the number of gram atom per mole, correspond to orders of magnitude differences in the distribution coefficients. Thus, if this term were the only term of importance, the distribution coefficient of $\mathrm{CeCl}_{3}$ would be $10^{1.34 \times 3}$ (about $1.05 \times 10^{4}$ ) greater than that for $\mathrm{PuCl}_{3}$. If the redox potential of the system is controlled by the $\mathrm{Mg}-\mathrm{MgCl}_{2}$ couple, then all of the chlorides above $\mathrm{MgCl}_{2}$ would be expected to favor the salt phase and all below $\mathrm{MgCl}_{2}$, the metallic alloy phase. Thus, a separation of uranium and plutonium from the more noble fission products and cladding metals would expect to be achieved by oxidizing $U$, and $P u$ into the molten salt with $\mathrm{MgCl}_{2}$. However, when such simple schemes are attempted for the separation of $\mathrm{U}$ and $\mathrm{Pu}$ from each other and the rare earth fission products, the large effect of the oxidation and reduction potentials on the distribution coefficient must be considered. The difficulty of separating $\mathrm{Pu}$ from the rare carth fission products due to the leveling effect of the reduction potential stymied the development of a high decontamination pyrochemical process for many years. The discovery of copper-magnesium alloys as a metallic solvent system by Knighton ${ }^{5}$ led to the development of a high decontamination pyrochemical process. The favorable reduction potentials for $\mathrm{U}, \mathrm{Pu}$, and the rare earth metals in copper-magnesium alloys made the high scparations possible.

To illustrate the application of eq. (3), the computation of the distribution coefficient of uranium between molten $\mathrm{MgCl}_{2}$ and liquid $\mathrm{Mg}-\mathrm{Zn}$ alloys will be discussed in detail. The numerical details are given in Table 2.

The reaction potential was computed from the free energy of formation data selected 
by $\mathrm{Paniratz}{ }^{7}$ for $\mathrm{MgCl}_{2}$ and by $\mathrm{Fuger}^{8}$ for $\mathrm{UCl}_{3}$. Since the temperature, $1073 \mathrm{~K}$, was bclow the melting point of $\mathrm{UCl}_{3}(1110 \mathrm{~K})$, the free encrgy of $\mathrm{UCl}_{3}$ had to be corrected for the free energy of fusion. For the molten salt phase, valucs of the frce energies for the liquid (super-cooled if necessary) salts should be used so that published molten salt activity data for the constituents can be used. The value of the reaction potential at $1073 \mathrm{~K}$ was found to be -3.999 .

The reduction potential was computed from the activity of niagnesium in liquid $\mathrm{Mg}-\mathrm{Zn}$ alloys reported by Chiotti and Stevens ${ }^{9}$ and the activity coefficients of uranium in liguid zinc $^{10}$ and magnesium alloys ${ }^{11}$. It was assumed that the small concentration of uranium in the liquid alloys had a negligible effect on the activities of magnesium, and the activity could be computed from the data on the binary alloys, as shown in column 3 of Table 2 . The activity coefficient of uranium in the liquid binary $\mathrm{Mg}-\mathrm{Zn}$ alloy solvent, column 4 in Table 2, was computed using the Darkin ${ }^{12}$-Alcock-Richardson ${ }^{13}$ approximation:

$$
\log \gamma_{U}=x_{M g} \log \gamma_{U(M g)}+x_{Z_{n}} \log \gamma_{U\left(Z_{n}\right)}-\Delta G_{M I g-Z_{n}}^{z^{3}} / 2.3 R T
$$

in which $\gamma_{U(M g)}$ and $\gamma_{U\left(Z_{n}\right)}$ are the activity coefficients of uranium in pure liquid magnesium and zinc, respectively, and $\Delta G_{M g-Z_{n}}^{a}$ is the excess free energy of mixing of the Mg-Zn alloy whose composition is given by the atom fractions $x_{M g}$ and $x_{Z_{n}}$. At $1073 \mathrm{~K}$ the activity coefficients of uranium in liquid $\mathrm{Zn}$ and $\mathrm{Mg}$ are 0.155 and $3.131 \times 10^{4}$, respectively. The uranium-zinc system was studied using a high temperature EMF method, whilc the activity coefficient of uranium in liquid magnesium can be computed from its solubility in liquid magnesium since the equilibrium phase is solid uranium. Both of these activity coefficients use solid uranium as the reference state even though used for an alloy in the liquid state. This unusual convention for uranium can be traced back to the use of high temperature EMF methods for the study of the thermodynamics of liquid alloys of aranium and low melting metals $^{14}$. The cell EMF's were measured relative to a pure solid uranium clectrode. Also, the frce energy of formation of $\mathrm{UCl}_{3}$ used to compute the reaction potential is referenced to solid uranium.

The oxidation potential for this systen was computed by assuming that the activity of $\mathrm{MgCl}_{2}$ in these dilute solutions was unity. There are no experimental data for the activity of $\mathrm{UCl}_{3}$ in molten $\mathrm{MgCl}_{2}$. When the distribution coefficients for uranium were computed assuming that $\gamma_{\mathrm{UCl}_{3}}$ was unity, column 5 in Table 2, it was found that the values were larger than the experimental values ${ }^{15}$ by a constant factor, as shown in column 6 of Table 2 ( $0.252 \pm$ 0.009). This leads to an activity coefficient of $\mathrm{UCl}_{3}$ in molten $\mathrm{MgCl}_{2}$ of 1.79 . This value, which is equivalent to about 1500 cal., should be accepted with caution since it depends on the value used for the reaction potential. It is doubtful whether the individual values of the free energies of $\mathrm{UCl}_{3}$ and $\mathrm{MgCl}_{2}$ are known well cnough to place much confidence in 1.79 for the activity coefficient. However, these data suggest that only small deviations, possibly positive, from ideal behavior exist. This result is in sharp contrast with the large negative deviations from ideal behavior observed when a molten $\mathrm{LiF}-\mathrm{BeF}_{2}$ salt is used ${ }^{16,17}$. In these systems the formation of stable complexes in the molten salt greatly reduces the activity coefficient. 
The results of these computed values for the distribution cocflicient of uranium between $\mathrm{MgCl}_{2}$ and $\mathrm{Mg}-\mathrm{Zn}$ are compared to the experimental data reported by Knighton ${ }^{15}$ in fig. 1. It is secn that the computed curve fits the experimental data very well.

Similar computations of the distribution of plutonium between molten $\mathrm{MgCl}_{2}$ and liquid $\mathrm{Zn}-\mathrm{Mg}$ alloys indicate that an activity coefficient for $\mathrm{PuCl}_{3}$ in molten $\mathrm{MgCl}_{2}$ of 6.68 土 0.08 is required to fit the experimental data.

While these illustrations of the computation of distribution coefficients ate for systems in which the redox potential is controlled by an auxiliary redox couple, i.e., the $\mathrm{Mg}-\mathrm{MgCl}_{2}$ couple, the same procedure can be used to compute the distribution coefficients of systems where two or more different actinides or fission products are present in equilibrium. For example, if a mixture of uranium and plutonium were dissolved in a liquid metal, for example cadmium, and then placed in contact with a molten mixture of alkali metal chlorides containing a small amount of dissolved $\mathrm{CdCl}_{2}$, the uranium and plutonium in the liquid metal would be transferred (oxidized) into the salt until the concentration of $\mathrm{CdCl}_{2}$ in the salt would be extremely snall (note the large differences in stability, Table 1.). The uranium and plutonium would exist in equilibrium according to the equation:

$$
\mathrm{UCl}_{3}(\text { salt })+P u(\text { alloy })=P u C l_{3}(\text { salt })+U(\text { alloy })
$$

In this example, the ratio of the distribution coefficients of uranium and plutonium depends on the same three terms used to analyze eq. (3). Thus, it is necessary to know the free energies of formation of $\mathrm{UCl}_{3}$ and $\mathrm{PuCl}_{3}$, the activities coefficients of $\mathrm{Pu}$ and $\mathrm{U}$ in liquid cadmium, and the activity cocflicients of $\mathrm{UCl}_{3}$ and $\mathrm{PuCl}_{3}$ in the molten salt mixture. It would be expected that the free energies and the activity coefficients in liquid cadmium woulc be most important in determining the ratio of distribution coefficients. In this case, the ratio of distribution co efficients is equal to the mole (atom) fraction equilibrium constant, which coul $\mathrm{d}$ be used to compute the compositions of the liquid metal and molten salt phases.

\section{Thermodynamics of salt transport processes}

Transfer from one liquid alloy through a molten salt to another liquid alloy is the main pyrochemical process used for the recovery and purification of uranium and plutonium. These two oxidation-reduction steps can be used to separate uranium and plutonium from the more noble fission product metals and the stainless steel (cladding) metals. By the use of more than one acceptor alloy, it is possible to prepare two product strcams, one plutonium-rich and one uranium-rich. Only small separations from the rare-earth fission products are obtained in salt transport processes. If high atcontaminations from the rare earths are requircd then separate counter current extraction steps must be used prior to the salt transport step. ${ }^{4}$

The salt transport process will be considered first, but as will be seen, the same relations are applicable to the analysis of both the salt transport and the electrotransport processes. The liquid alloy in which the uranium and plutonium are initially dissolved is referred to as the donor while the liquid alloy to which uranium or plutonium are transferred is referred to as the acceptor(s). In the electiotransport process these two liquid alloys are the anode and cathode(s), respectively. At the donor the following reaction occurs:

$$
U(d)+\frac{3}{2} M_{g C l}(s)=U C l_{3}(s)+\frac{3}{2} M g(d)
$$


while at the acceptor the reverse reaction occurs:

$$
U C l_{3}(s)+\frac{3}{2} M g(a)=U(a)+\frac{3}{2} M g C l_{2}(s)
$$

where $d, s$, and $a$ refer to the donor, salt, and acceptor, respectively. The overall reaction is:

$$
U(d)+\frac{3}{2} M g(a)=U(a)+\frac{3}{2} M g(d)
$$

which leads to the equilibrium relation:

$$
\frac{a_{U(a)} a_{M g(d)}^{3 / 2}}{a_{U(d)} a_{M g(a)}^{3 / 2}}=1
$$

in which the $a$ 's are activities. When the activities are exprcssed as the product of the atom fraction $(x)$ and the activity coefficient $(\gamma)$, one obtains:

$$
\frac{x_{U(a)}}{x_{U(d)}}=\left(\frac{a_{M g(a)}}{a_{M g(d)}}\right)^{3 / 2} \frac{\gamma_{U(d)}}{\gamma_{U(a)}}
$$

Therefore, the ratio of the atom fractions in the two alloys when the transfer is complete depends on the activities of magnesium and the ratio of the activity coefficients in the two alloys. Since the activity coefficients can have very large or small values in these systems, the fraction transferred is very dependent on the compositions of the two alloys. When both uranium and plutonium are present, and equilibrium has been established amoung $\mathrm{Pu}, \mathrm{U}$, and $\mathrm{Mg}$, the following relation is obtained:

$$
\frac{a_{U(a)}}{a_{U(d)}}=\frac{a_{P u(a)}}{a_{P u(d)}}
$$

This equation indicates that the separations which may be obtained are dependent on the activity coefficients of $\mathrm{U}$ and $\mathrm{Pu}$ in the two alloys. If the activity coefficients have the same ratio in the two alloys, then the ratio of uranium to plutonium in the two alloys would be the same.

The analysis thus far has asumed that the two alloys were single phase i.e., complete solubility of uranium and plutonium in each alloy. Since limited solubility in the alloys would have a large effect on the operation of practical processes it will now be considered. It is convenient to use a different approach to describe the effect of limited solubility on the salt transport process. This approach uses the distribution coefficient and solubility data directly. The distribution data can be computed from thermodynamic data using the method described, in section 3, while solubilities can be computed using methods described elsewhere ${ }^{19,20}$. The analysis also assumes that the transfer from the donor to the acceptor is carried out in a stepwise fashion, i.e., the salt is first contacted with the donor alloy, allowed 
to rcach equilibrium, then moved to a separate vessel containing the acceptor alloy where equilibrium is established. The salt is then returned to the donor alloy vessel.

For this analysis, the distribution zoefficients $K_{D}$ and $K_{A}$ are defined as $\frac{w_{S}}{w_{D}}$ and $\frac{w_{S}}{w_{A}}$, in which $w_{S}, w_{D}$, and $w_{A}$ are the weight fractions of the solute in the salt, donor, and acceptor, respectively.

For the transport to occur or continuc, the concentration of uranium or plutonium in the salt phase when in equilibrium with the donor must be greater than the concentration when in equilibrium with the acceptor; therefore $K_{D} w_{D}>K_{A} w_{A}$. When the concentration in the salt returning from the acceptor is equal to the concentration in equilibrium with the donor, transfer will stop and the maximum transfer will be achieved, and $K_{D} w_{D}=K_{A} w_{A}$. Therefore, when the maximum transfer has occurred:

$$
\frac{w_{A}}{w_{D}}=\frac{K_{D}}{K_{A}}
$$

This equation is equivalent to eq. (10). To model the stepwise transfer process, the fractional transfer will be calculated as a function of the distribution coefficients, the amount of donor, $\mathrm{D}$, salt, $\mathrm{S}$, acceptor, $\mathrm{A}$, and the number of transfer cycles.

From the mass balance and the definition of the distribution coefficient, the fraction $F_{D}$ of the solute ( $\mathrm{U}$ or $\mathrm{Pu}$ ) in the donor and salt transferred to the acceptor is given by:

$$
F_{D}=\frac{K_{D}(S / D) x+z}{K_{D}(S / D)+1}
$$

where $x$ is the fraction of salt transferred and $z$ is the fraction of donor entrained with the salt. A similar expression is obtained for the fraction of solute back-transferred from the acceptor to the donor, except that $K_{D}$ is replaced with $K_{A}$ and $D$ by $A$.

The fraction transferred after n cycles, $\Phi_{n}$, is given by:

$$
\Phi_{n}=\left(1-\frac{F_{A}}{1-F}\right)\left(1-F^{n}\right)
$$

in which $F=\left(1-F_{A}\right)\left(1-F_{D}\right)$. Since $F$ is less than unity, the maximum fractional transfer, $\Phi_{\text {max }}$, is given by:

$$
\Phi_{\max }=\left(1-\frac{F_{A}}{1-F}\right)
$$

To a good approximation $(\sim 0.1 \%), \Phi_{\max } \simeq 1-f$, where $f=\frac{F_{A}}{F_{D}}$. If there is no entrainment of either alloy during the transfer (i.e, $z=0$ ), then the maximum fractional transfer is given by:

$$
\boldsymbol{\Phi}_{\text {max }}=\frac{K_{D} A}{K_{A} D+K_{D} A+K_{A} K_{D} S}
$$

This relation shows that complete transfer would be possible if $K_{A}=0$. This expression may also be derived from the mass balance, the definitions of the distribution coefficients, and eq. (12). 
Since $1-F^{n}$ varies from 0 to 1 as $n$ varies from 0 to $\infty$, the number of cycles, $n$, required to obtain a given fraction, $P$, of the maximum possible transfer, $\Phi_{\max }$, is given by:

$$
n=\frac{\ln (1-P)}{\ln F}
$$

The value of $n$ increases rapidly when $F$ increases above 0.8 .

The above equations were derived with the assumptions that all of the solutc was initially present in solution in the donor and salt (none initially ir the acceptor) and that all of the solute transferred to the acceptor was completely soluble. The amount of solute transferred to the acceptor, $\Phi w_{d, i}\left(K_{D} S+D\right)$, is dircctly proportional to the initial concentration, $w_{d, i}$, in the donor. If the concentration in the donor is low, as would be the case if it's solubility in the donor were low, then the amount transferred would be small even though the fraction transferred were large. With a low concentration in the salt (i.e., $K_{D} w_{d}$ ), when in contact with the donor, a large number of cycles would be nceded to transfer a small amount of solute. This would not yield a practical process.

The amount transferred can also be limited by $\Phi_{\max }$ when $F_{D}$ is not much greater than $F_{A}$, as would be the case if $K_{D}$ is not much greater than $K_{A}$. In this case, the amount transferred can be increased by beginning the salt transfer with a part of the initial charge as an insoluble metallic phase. This has two adyantages: the total amount of solute available for transfer is larger, and the rate of transfer is greater. This latter follows from the fact that as long as undissolved solid remains in the donor, the fraction transferred from the donor will remain constant and be greater than would be the case if the the concentration in the donor decreased with each cycle.The fraction transferred after $n$ cycles is given by:

$$
\Phi_{n}^{\prime}=\frac{p F_{D}\left(1-F_{A}\right)}{F_{A}}\left(1-\left(1-F_{A}\right)^{n}\right)
$$

where $p$ is the fraction of the total solute initially in solution in the donor and salt. The value of $p$ may be calculated from the total amount of solute in the donor initially, the distribution coefficient, and the solubility of the solute in the donor. This equation is valid only when excess solute is present as an insoluble metallic phase. When all of the solid has dissolved, eq. (14) must be used to calculate the fractional transfer for the remaining part of the transfer. Starting the salt transfer with part of the solute as an insoluble metallic phase in the donor will increase the maximum transfer over the value that can be obtained starting with all of the solute in solution, and will decrease the number of cycles nceded. It is also found that there is an optimal value for $p$ to achieve a given fractional transfer with the minimum number of cycles. These effects can bc significant for practical processes. For example, a system for which the maximum fractional transfer was $97.3 \%$ (for an "infinite" number of cycles), would achieve a fractional transfer of $99 \%$ in 21 . cycles if $20 \%$ of the initial charge was in solution with the remaining $80 \%$ present as a solid metallic phase. It should be noted that the solubility of the solute in the donor was not low even though only $20 \%$ of the initial charge was in solution. This case and the case discussed in the previous paragraph should not be confused. 
If the solubiity of the solute in the acceptor is low, then the back transfer of solute to the donor will be decreased and the maximum fractional transfer will be increased. If the acceptor becomes saturated after the first transfer cycle, then the fraction transferred to the acceptor after $n$ cycles is given by:

$$
\Phi_{n}^{\prime \prime}=\left(1-\frac{a}{F_{D}}\right)\left(1-\left(1-F_{D}\right)^{n}\right)
$$

where $a$ is the fraction of the original charge that is returned each aycle tr the done frnm in: acceptor after the acceptor has become saturated. 'This quantity will be constant throughout the iransfer. The value of $a$ can be computed from the total amount of solute initially present, the distribution roefficient, $K_{A}$ the solubility of the solute in the acceptor, and the amounts of salt and acceptor. A small value for the solubility of the solute in the acceptor can be used to compensate for a large value of $K_{A}$. The maximum fractional transfer is obtained from eq. (19) by setting the last factor equal to unity:

$$
\Phi_{\max }^{\prime \prime}=1-\frac{a}{F_{D}}
$$

It is possible to combine an excess of solute in the donor with a low solubility in the acceptor to obtain a highly efficient process. An examplc of such a system is discussed by Knighton ${ }^{5}$. In this example uranium is recovered and purified by being salt transported from a copper-magnesium alloy through a molten $\mathrm{MgCl}_{2}$ salt to a magnesium-zinc alloy. Uranium has a moderate solubility ( $1 \%)$ in the $\mathrm{Cu}-\mathrm{Mg}$ alloy but a low solubility $(0.025 \%)$ in the $\mathrm{Mg}-\mathrm{Zn}$ alloy. The distribution coefficients are 0.45 for the $\mathrm{Cu}-\mathrm{Mg}$ donor and 0.3 for the $\mathrm{Mg}-\mathrm{Zn}$ acceptor. The insoluble uranium forms an intermetallic phase, $\mathrm{UCu}_{5}$, in the donor and is present as pure metallic uranium in the acceptor. In a kilogram scale experiment $99 \%$ of the uranium was recovered in 27 transfer cycles. ${ }^{21}$ In addition, removals of over $99 \%$ werc obtained for zirconium and other noble metal fission products.

The salt transport process can be used to separate uranium and plutonium from the more noble fission product elements. The decontamination factor,D.F., is defined as:

$$
\text { D.F. }=\frac{\Phi_{U \text { or } P_{u}}}{\Phi_{\text {impurity }}}
$$

For the purpose of this discussion the fractional transfer of $\mathrm{U}$ or $\mathrm{Pu}$ can be set equal to one. The fractional transfer for the impurity can be shown to be approximately equi.? to $n\left(K_{D i} \frac{S}{D} x+z\right)$ where $K_{D i}$ is the distribution coefficient of the impurity, and $n$ is the number of cycles needed to obtain the required high recovery of uranium or plutonium. To obtain this result it is assumed that $F_{A}=0$ and $K_{D i} \frac{S}{D}$ is small compared to one. Hence the D.F. is given by:

$$
D . F .=\frac{1}{n\left(K_{D i} \frac{S}{D} x+z\right)}
$$

Since $K_{D i}$ is be expected to be small, the amount of donor entrained with the salt becomes important and may, in some cases, limit the decontamination which can be achieved. Where 
very high decontaminations are required, it may be necessary to salt transport to an intermediate acceptor alloy, which then acts as the donor for the final acceptor. In a test case where a D.F. of 320 was obtained with no entrainment, the D.F. was $r=d u c e d$ to 90 when $0.1 \%$ entrainment occurred.

The above analysis, eq. 12-22, is based on the assumption that the distribution coefficients are constant during the salt transport process. However, during the transfers, magnesium is sent from the acceptor to the donor. This will lead to a change in the activities of the solutes in the two alloys and change the distribution coefficients. For a more exact treatment, these changes must be considered. The treatment given above allows the computation of the overall performance of a proposed process configuration to the accuracy needed for process development. The treatment adds to the understanding of the salt transport process.

\section{Thermodynamics of electrotransport processes}

The analysis of the electrotransport prccesses is similar to that used for the salt trunsport process. In this case the transfer is done by electrolyzing (i.e., oxidicing) $U$ and $P u$ into the salt at the anode and electrodepositing an equivalent amount at the cathode. Some $U$ and $\mathrm{Pu}$ must be present in the salt before the electrolysis is started. This could be obtained by adding a mild oxidizing agent, most likely a salt of the anode solvent metal. The composition of the mixture of $\mathrm{Pu}$ and $\mathrm{U}$ deposited at the cathode depends on the kinetic factors that control electrodeposition from molten salts into a liquid alloy electrode. However, aftcr some $U$ and $P u$ has been transferred to the cathode, there is a tendency fo- equilibrium to be maintained between the salt and the alloy at each electrode. Hence, at each electrode the following equilibrium will exist:

$$
U C l_{3}(\text { salt })+P u(\text { alloy })=U(\text { alloy })+P u C l_{3}(\text { salt })
$$

which leads to the following equilibrium relation:

$$
\frac{a_{U(\text { allay })^{a} p_{u C l}(\text { sall })}}{a_{\left.P_{u(a l l o y}\right)^{a} U C l_{3}(\text { ealt })}}=K_{a}
$$

where the $a$ 's are activities and $K_{a}$ is the activity equilibrium constant. If there are no large concentration differences in the salt, then the activities in the salt will be the same at each electrode, and one obtains the relation:

$$
\left(\frac{a_{U}}{a_{. P u}}\right)_{\text {anode }}=\left(\frac{a_{U}}{a_{P u}}\right)_{\text {cathode }}
$$

which can be written in the same form as eq. (11) if one assumes that donor $\equiv$ anode and acceptor $\equiv$ cathode. This equation, when written in the same form as eq. (11), shows that the EMF for both possible cells is the same value:

$$
-n F E=R T \ln \frac{c_{U(a)}}{a_{U(c)}}=R T \ln \frac{a_{P u(a)}}{a_{P u(c)}}
$$


in which $a$ and $c$ refer to the anode and cathode, sespectively. The condition expressed by eq. (25) is referred to as the equal EMF condition and is an important result for the understanding of the operation of the elecirotransport process. This condition connects the two liquid alloy electrodes in the analysis of the system. During the operation of the electrotransport process; the total number of cquivalents of solute in the salt (i.e., $\mathrm{UCl}_{3}$ and $\mathrm{PuCl}_{3}$ ) is constant. This was also true of the salt transpcit process in which case $\mathrm{MgCl}_{2}$ has to be included with the $\mathrm{UCl}_{3}$ and the $\mathrm{FuCl}_{3}$. The total number of equivalents of solute metals, at any given juncture of the transport process, in each licuid electrode is constant although the composition will change as equilibriurn is established.

To use eq. (24) and (25) in the analysis that follows, the activities are replaced by concentration units. The equilibrium relation, eq. (24), may be written in terms of atom (mole) fractions:

$$
\frac{x_{U} x_{P u C l_{3}}}{x_{U C l_{3}} x_{P u}}=K_{a} \frac{\gamma_{P u} \gamma_{U C l_{3}}}{\gamma_{U} \gamma_{P u C l}}
$$

in which the $\gamma$ 's are activity coefficients. The right-hand side of eq. (27) is defired as $K_{x}$, the atom fraction equilibrium constant. While the activity coefficients are functions of the solute concentrations in the alloys, the variation with concentration is not large, and the $\gamma$ 's can be considered constant for most computations. If more accurate results are required, the $\gamma$ values can be adjusted for the actual concentrations found, and the computation repeated as often as needed to obtain the required accuracy. The atom fraction of $U$ is given by $\frac{n_{U}}{\tau_{S U}+n_{P_{u}}+n_{C d}}$, where the $n$ 's are moles of the subscripted element and cadmium is assumed to be the solvent metal. A similar expression is obtained for the atom fraction of $\mathrm{Pu}$. The denominators cancel when the ratio is taken. Similar expressions are obtained for the mole fractions of the salts; again the denominators cancel when the ratio is taken. This allows the equilibrium relation to be written:

$$
\left(\frac{n_{P u C l_{3}}}{n_{U C i_{3}}}\right) \times\left(\frac{n_{U}}{n_{D_{u}}}\right)=K_{x}
$$

In a similar way the equal EMF relation can be written:

$$
\frac{n_{U, a}}{n_{P u, a}}=\frac{n_{U, c}}{n_{\dot{r} u c}}
$$

These equations, (28) and (29), apply to the liquid phases of the two electrodes. To complete the description of the system, three mass balance relations are needed:

$$
\begin{gathered}
n_{U, a}+n_{U, c}+n_{U C l_{3}}=n_{U} \\
n_{P u, a}+n_{P u, c}+n_{P u C l_{3}}=n_{P u} \\
n_{U C l_{3}}+n_{P u C l_{s}}=n_{a}
\end{gathered}
$$

in these equations $n_{U}, n_{P u}$, and $n_{s}$ are the total amounts of uranium, plutonium, and salts in the system. One additional condition is needed to specify the system, the total amount 
of solute transferred to the cathode. This can be stated in a variety of ways. For the case that all of the solute is in solution in the cathode, the following relation may be used:

$$
n_{U, c}+n_{P u, c}=n_{c}
$$

in which $n_{c}$ is the total solute in the cathode. To determine the distribution of $U$ and $\mathbf{P u}$ between the anode,salt, and cathode, eq. (28) is solved for $n_{\mathrm{PuCl}_{3}}$. This is done by calculating the first ratio using eq. (30.3) and the second ratio using cq. (30.1), (30.2) and (29). The result, when both liquid clectrodes are single (liquid) phases, is the following guadratic equation in which $n_{P_{u} C_{3}}$ has been replaced by $x$ :

$$
\frac{x}{n_{s}-x} \times \frac{n_{U}-n_{s}+x}{n_{P_{u}}-x}=K_{x}
$$

Once $x$ is known, the amount of $U$ and $P u$ in the anode and cathode can be computed by substitution in eq. (30). It is found that eq. (31) only needs to be solved once to obtain the ratio $\frac{n_{U, c}}{n_{P u, c}}$, which is constant through out the transfer (if the small variations in the activity coefficients with concentration are neglected). Values of $n_{U, c}$ and $n_{F u, c}$ are obtained for different amounts of transfer to the cathode by changing the value of $n_{c}$ in eq. (30.4). When either of the liquid alloys is not single phase, the procedure is similar but the manner in which the second factor in eq. (28) is calculated is changed to include the solubility of the solute(s) in the liquid alloy(s).

As the electrotransport proceeds, the EMF of the system changes due to the change in the ratio of the atom fractions of uranium (or plutonium) in the two liquid alloy electrodes. Since the atom fraction ratio is that of uranium (or plutonium) between two different liquid alloys, the total moles in each alloy used to convert the moles of uranium to atom fraction does not cancel out; the ratio is given by the equation:

$$
\frac{x_{U, a}}{i U_{, c}}=\frac{n_{U, a}}{n_{U, c}} \times \frac{n_{U, c}+n_{P u, c}+n_{C d, c}}{n_{U, a}+n_{P u, a}+n_{C d, a}}
$$

Since the moles of $\mathrm{Cd}$ in each alloy electrode is usually much larger than the moles of solute the latter can often be neglected. The EMF, $E$, is given by the relation:

$$
E=\frac{R T}{n F} \ln \frac{x_{U, a}}{x_{U, c}}
$$

The recovery and separation of uranium and plutonium by electrotransport will be discussed by the use of two numerical examples. The electrotransport of a mixture of plutonium and uranium from one liquid cadmium alloy to another will be used in these examples. The first step is to estimate the value of $K_{x}$, the atom fraction equilibrium constant for the distribution of uranium and plutonium between liquid cadinium and a molten salt. The value of $K_{a}$ is computed from $\Delta G^{\circ}$ using the relation:

$$
-R T \ln K_{\mathrm{a}}=\Delta G f_{P_{\mathrm{u}} \mathrm{Cl}_{\mathrm{s}}}-\Delta G f_{U G \mathrm{l}_{\mathrm{s}}}
$$


Valucs of the free energies of formation were obtaincu' from Fuger ${ }^{8}$. At $773 \mathrm{~K}, \Delta G^{\circ}$ was found to be $-21835 \mathrm{cal} / \mathrm{mol}$, which gives a value for $K_{a}$ of $1.48 \times 10^{6}$. Values for $\gamma_{P_{u}}$ and $\gamma U$, eq. (27), were obtained from the EMF studies of the $\mathrm{Cd}-\mathrm{Pu}^{24}$ and $\mathrm{Cd}-\mathrm{U}^{25}$ systems. Both activity coefficients are dependent on the solute concentration in the liquid Cd alloy. $\Lambda t 773$ $\mathrm{K}$ the values for $\gamma_{P_{u}}$ vary from $1.39 \times 10^{-4}$ to $2.37 \times 10^{-4}$ as the concentration varies from zero to the saturation value $(1.805 \mathrm{a} / \mathrm{o})^{24}$, while for $\gamma_{U}$ the values vary from 81.3 to 88.7 as ine concentration varies from zero to the saturation value $(1.128 \mathrm{a} / 0)^{26}$. The equilibrium solid phases are the intermetallic compound $P u C a_{6}$ and clemental uranium. The ratio $\frac{\gamma P_{u}}{\gamma U}$ varies from $1.71 \times 10^{-6}$ to $2.67 \times 10^{-5}$ over the concentration range. The ratio of the $\gamma^{\prime} s$ for $\mathrm{PuCl}_{3}$ and $\mathrm{UCl}_{3}$ in the molten salt phase depends on the composition of the molten salt. There is a paucity of such data. For the present example the results reported in section 3 of this paper have been used. Hence, $\frac{\gamma_{U C l_{3}}}{\gamma_{P_{u} C l_{3}}}=0.267$. When these values of the activity coefficients are combined witl the value of $K_{a}$, the value of $K_{x}$ is found to vary from 0.68 to 0.93 . A value of 0.8 was selected for the numerical examples. The very large effect of the activity coefficients in the liquid alloys should be noted.

For these cxamples, a mixture of $82.5 \%$ uranium and $17.5 \%$ plutonium was assurned. This is approximatcly the composition of spent core fuel. The anode was assumed to contain 100 moles of cadmium, while the cathode contained 50 moles of cadmium. These choices were selected to illustrate some of the characteristics of electrotransport and do not represent the optimum choices for a practical process. In the first example, the amount of the U-Pu mixture was selected so that the anode would be initially just salurated with respect to uranium, while in the second example the anode was initially just saturated with respect to plutonium. Thus, in the first example all of the uranium and plutonium are initially in solution in the anode, while in the seccnd example a large fraction of the uranium is initially present as solid uranium. From the solubility data for uranium in liquid cadmium ${ }^{26}$, the initial charge in the first example contained 0.242 moles of $\mathrm{Pu}$ and 1.141 moles of $\mathrm{U}$. Ten percent of the initial charge was tiansferred to the salt to furnish the solute chlorides needed for the electrotransport. In a practical process, the molten salt may contain $\mathrm{UCl}_{3}$ and $\mathrm{PuCl}_{3}$ irom the previous batch.

The results of the numerical computations are shown in Table 3. Column 1 is the percent of the $\mathrm{U}$ and $\mathrm{Pu}$ initially in the anode (after $10 \%$ was oxidized into the salt) but then transferred to the cathode. The compositions of the anode and cathode are given in moles. At $55.7 \%$ transfer, the cathode becomes saturated in uranium. As more uranium is transferred to the cathode, the amount in solution in the cathode does not change; the excess adds to the metallic uranium precipitate. The ratio of $\mathrm{Pu}$ to $\mathrm{U}$ in the anode and cathode up to $55.7 \%$ transfer is constant and equal for the two liquid electrodes. This is what is expected, eq. (25), if the activity coefficients are equal in the two alloys and do not change with concentration. Once the cathode becomes saturated with uranium, these ratios are no longer constant. The transfer of uranium to the cathode, after saluration is achieved, results in less uranium in solution. The ratio of $\mathrm{Pu}$ to $\mathrm{U}$ in solution will increase for both liquid electrodes, as is seen for the anode. In the cathode, some of the uranium is not in solution and the overall $\mathrm{Pu}$-to- $\mathrm{U}$ ratio, which is shown in table 3 , will be increased by the amount 
Table 3

Electrotransport of uranium and plutonium

Anode:100 mol Cd; Cathode:50 mol Cd

$\mathrm{U}=1.141 \mathrm{~mol} ; \mathrm{Pu}=0.242 \mathrm{~mol}$

$10 \%[\mathrm{U}+\mathrm{Pu}]$ in salt; $773 \mathrm{~K}$

\begin{tabular}{lllllll}
{$[\mathrm{U}+\mathrm{Pu}]_{c}$} & \multicolumn{3}{c}{ Anotc(moles) } & \multicolumn{2}{c}{ Cathode(moles) } \\
$\%$ & $\mathrm{Pu}$ & $\mathrm{U}$ & {$[\mathrm{Pu} / \mathrm{U}]$} & $\mathrm{Pu}$ & $\mathrm{U}$ & {$[\mathrm{Pu} / \mathrm{U}]$} \\
8.0 & 0.204 & 0.941 & 0.217 & 0.018 & 0.082 & 0.217 \\
16.0 & 0.186 & 0.859 & 0.217 & 0.036 & 0.164 & 0.217 \\
32.1 & 0.150 & 0.694 & 0.217 & 0.071 & 0.229 & 0.217 \\
40.1 & 0.133 & 0.612 & 0.217 & 0.107 & 0.493 & 0.217 \\
55.7 & 0.098 & 0.453 & 0.217 & 0.123 & 0.570 & 0.217 \\
59.5 & 0.092 & 0.410 & 0.225 & 0.128 & $0.613 \dagger$ & 0.209 \\
69.8 & 0.075 & 0.300 & 0.252 & 0.143 & $0.726 \dagger$ & 0.198 \\
73.3 & 0.058 & 0.210 & 0.278 & 0.158 & $0.815 \dagger$ & 0.191 \\
85.6 & 0.042 & 0.137 & 0.304 & 0.173 & $0.893 \dagger$ & 0.194 \\
91.1 & 0.025 & 0.075 & 0.331 & 0.188 & $0.957 \dagger$ & 0.197 \\
95.7 & 0.013 & 0.039 & 0.348 & 0.198 & $0.994 \dagger$ & 0.199
\end{tabular}

†Cathode contains $0.57 \mathrm{~mol} \mathrm{U}$ in solution.

present as an ins sluble solid phase. The $\mathrm{Pu} / \mathrm{U}^{\prime}$ ratio in the cathode remains almost constant because the effect of the increase in the $\mathrm{Pu} / \mathrm{U}$ ratio due to the decrease of the $\mathrm{U}$ in solution is almost balanced by the decrease caused by the additional uranium present as solid. The $\mathrm{Pu} / \mathrm{U}$ ratio in solution in the cathode increases as the amount of solid increases, as would be seen if the amoint of $\mathrm{Pu}$ in solution is divided by $0.57 \mathrm{~mol}$, the amount of uranium in solution. Equation (29) applies only to the uranium and plutonium in solution.

From the solubility of $\mathrm{Pu}$ in $\mathrm{Cd}^{24}$, the initial charge in the second example contains 2.19 moles of $\mathrm{Pu}$ and 12.35 moles of uranium. One percent of this charge was transferred to the salt to furnish the $\mathrm{PuCl}_{3}$ and $\mathrm{UCl}_{3}$ required for the electrolysis. The anode initially contains solid uranium as an insoluble phase. The numerical details of the computation are given in Table 4. As the solute is moved from the anode to the cathode, the total amount of uranium in solution increases due to the dissolution of some of the uranium at the anode.

This will decrease the $\mathrm{Pu} / \mathrm{U}$ ratio in solution, as is seen for both the anode and the cathode in Table 4. The decrease in the overall $\mathrm{Pu} / \mathrm{U}$ ratio in the anode as the transfer takes place will be reduced by the dissolution of solid uranium. At $10.33 \%$ transfer, the cathode becomes saturated with respect to uranium. Further transfers of solute from the anode to the cathode simply move solid uraniun from the anode to the uranium solid phase in the cathode. The total amount of $\mathrm{Pu}$ and $\mathrm{U}$ ir solution does not change, and hence the composition of the two liquid phases is constant. The overall $\mathrm{Pu} / \mathrm{U}$ ratio increases in the anode and decreases in the cathode. Since no additional $\mathrm{Pu}$ is transferred to the cathode during this phase of the transfer, a Pu-rich solution can be obtained in the anode. In a practical process, this $\mathrm{Pu}$ could be recovered by transfer to a second cathode. This is similar 


\section{Table 4}

Electrotransport of uranium and plutonium

$$
\begin{gathered}
\text { Anode: } 100 \mathrm{~mol} \mathrm{Cd} \text {; Cathode: } 50 \mathrm{~mol} \mathrm{Cd} \\
\mathrm{U}=12.35 \mathrm{~mol} ; \mathrm{Pu}=2.19 \mathrm{~mol} \\
1 \%[\mathrm{U}+\mathrm{Pu}] \text { in salt; } 773 \mathrm{~K}
\end{gathered}
$$

\begin{tabular}{lllllll}
{$[\mathrm{U}+\mathrm{Pu}]_{c}$} & \multicolumn{3}{c}{ Anode(moles) } & \multicolumn{2}{c}{ Cathode.(moles) } \\
$\%$ & $\mathrm{Pu}$ & $\mathrm{U} \dagger$ & {$[\mathrm{Pu} / \mathrm{U}]$} & $\mathrm{Pu}$ & $\mathrm{U}$ & {$[\mathrm{Pu} / \mathrm{U}]$} \\
0.63 & 2.066 & 10.24 & 0.202 & 0.050 & 0.028 & 1.81 \\
2.58 & 1.918 & 10.15 & 0.184 & 0.200 & 0.119 & 1.68 \\
5.37 & 1.722 & 10.00 & 0.172 & 0.400 & 0.265 & 1.51 \\
8.47 & 1.525 & 9.81 & 0.155 & 0.600 & 0.449 & 1.34 \\
10.33 & 1.418 & 9.69 & 0.146 & 0.709 & 0.570 & 1.24 \\
16.15 & 1.418 & 8.97 & 0.158 & 0.709 & $1.291 \ddagger$ & 0.549 \\
32.30 & 1.418 & 6.97 & 0.204 & 0.709 & $3.291 \ddagger$ & 0.216 \\
48.45 & 1.418 & 4.97 & 0.286 & 0.709 & $5.291 \ddagger$ & 0.134 \\
64.59 & 1.418 & 2.97 & 0.478 & 0.709 & $7.291 \ddagger$ & 0.097 \\
79.33 & 1.418 & 1.141 & 1.243 & 0.709 & $9.12 \ddagger$ & 0.078
\end{tabular}

†Anode contains $1.141 \mathrm{~mol} \mathrm{U}$ in solution. †Cathode contains $0.5705 \mathrm{~mol} \mathrm{U}$ in solution. to the way that $\mathrm{Pu}$ and $\mathrm{U}$ are separated in the salt transport process where two different acceptors are used.

The EMF as a function of $[\mathrm{U}+\mathrm{Pu}]$ transferred was computed for the two examples given in Tables 3 and 4 using eqs. (32) and (33). The results are shown in fig. (2). A positive EMF is based on the assumption that the anode would be ricgative in the conventional sense, i.e., electrons would leave the system at the anode. This assumes that $\mathrm{U}$ and $\mathrm{Pu}$ are oxidized at the anode and reduced at the cathode. The two curves indicate that the EMF's for both systems are positive initially, and that both systems would spontaneously transfer $U$ and $\mathrm{Pu}$ from the anode to the cathode if the two electrodes were connected with an electronic conductor. This is expected since the activities of both $\mathrm{Pu}$ and $\mathrm{U}$ are initially greater in the anode. As the electrolysis continues, the EMF will decrease since the trasisfer of $\mathrm{Pu}$ and $\mathrm{U}$ to the cathode will increase their activities and eventually reach zcro when the activities are equal. Further transfer to the cathode requires an external electrical power source.

For the $A B C$ curve from the first example, Table 3, additional transfer after the zero EMF is achieved results in a system that would spontaneously transfer $\mathrm{U}$ and $\mathrm{Pu}$ in the opposite direction if the two electrodes were connected with an electronic conductor. The rapid decrease in the $\mathrm{Pu}$ and $\mathrm{U}$ in solution after the cathode becomes saturated increases the rate of decrease of the EMF as seen in the BC segment. Once the cathode becomes saturated with uranium, its activity will be constant and further transfers of uranium to the cathode will not increase its activity. This is the reason for the difference in curvature of the two segments of curve $A B C$.

The curve DEF for the second example, Table 4, has two segments. The first segment corresponds to the transfer from the saturated (with respect to $U$ ) anode to the unsaturated cathode. The activities in the cathode increase and the EMF decreases. At point $E$, both 
electrodes become saturated with respect to uranium, and hence the activities are equal and the EMF is zero. To move additional $U$ to the cathode, an external source of clectrical power must be applied. If the EMF is computed on the basis of the Pu contents of the two electrodes using the data in Table 4 and eqs. (32) and (33) a zcro value is obtained. If the small concentration dependence of the activity coefficients is included in the computation of the EMF, then the Pu contents of the two electrodes would have to be slightly adjusted. The conceritration would be decreased in the anode and increased in the cathode.

\section{Comparison of Salt Transport and Electrotransport}

The analysis presented in this paper treats both the salt transport and electrotransport as equilibrium processes. Both processes involve the establishment of equilibrium between two (or more) liquid alloy phases and a common molten salt phase with the restriction that the number of equivalents of solute in each phase is constant. This restriction is due to the fact that the transfer of solutes between a liquid alloy and a molten salt is an oxidationreduction process and the equivalents of solute oxidized (transferred to the molten salt) must be balanced by the equivalents reduced (transferred to the liquid alloy). The number of equivalents of solute in each phase is fixed by the initial composition of the system, i.e., the number of moles of solute in each alloy and in the salt. In the case of salt transport, $U$, $\mathrm{Pu}$ and $\mathrm{Mg}$ must be considered solutes since all three are involved in the oxidation-reduction reactions. Hence, at the end of the salt transfer, the sum of the number of equivalents of $U$, $\mathrm{Pu}$, and $\mathrm{Mg}$ in the donor alloy is the same as it was initially except that the proportions of each has changed since $U$ and $P u$ have been transferred to the acceptor. The same is true of the acceptor except the amount of $U$ and $P u$ is greater and balanced exactly by less $\mathrm{Mg}$. In the case of electrotransport, the number of equivalents of $\mathrm{U}$ and $\mathrm{Pu}$ in the anode and cathode change as the electrolysis occurs. However, the total number of equivalents of $U$ and $\mathrm{Pu}$ in the two alloys is constant, as is the number of equivalents of $\mathrm{U}$ and $\mathrm{Pu}$ in the salt. The tendency to establish equilibrium during electrotransport can be considered as a series of salt transport steps, in which the initial composition of the liquid alloy phases are being changed stepwise by the electrolysis. The composition of the liquid alloys is determined by the equilibrium relation and the condition that the activities in the molten salt are equal at both alloys. This latter condition yiclds the equal ENF relation in electrotransport (eq. (25)) and a similar relation (eqs. (9)-(11)) for salt transport.

To use these relations for practical computations it is necessary to convert to relations between composition variables. This is done by using either the atom (mole) fraction equilibrium constants or the distribution coefficients and the solubilities in the liquid alloys. The analysis presented in this paper can be used as the starting point for more detailed computations involving other solutes and other initial conditions. The effect of changing alloy composition on the activity coefficients must be computed using iterative methods, since the equations obtained when the dependence of the equilibrium constants or distribution coefficients on alloy composition is explicitly included are too complex to solve analytically.

\section{Acknowledgments}

The author wishes to acknowledge the valuable contributions of J.B. Knighton, R.K. Steunenberg, L. Burris, and R.D. Pierce to tliese studies, and to the many colleagues that participated in the experimental studies of the thermodynamics of liquid metal solutions. In 
particular, many extremely valuable discussions with W.E. Miller and H.M. Feder helped direct the theoretical developments to the solution of practical problems. It is appropriate to mention the many contributions to this field of Professor Premo Chiotti, with whom this author has had many spirited and enlightening conversations. These studies were carried out under the auspices of the US Atomic Energy Commission and the US Department of Energy.

\section{References}

[1] B. R. Seidel, D. L. Porter, L. C. Walters and G. L. Ilofman, ANS International Coní. on Reliable Fuels for Liquid Metal Reactors, pp 2-107-2-121 (September 1986)

[2] R. K. Steunenberg, R. D. Pierce and L. Burris, Pyrometallurgical and Pyrochcmical Fuel Processing Methods, Progress in Nuclear Energy, Serics III, Process Chemistry, Vol. 4, pp 461-504, Pergamon Press, (Oxford 1969)

[3] P. Chiotti and S. J. S. Parry,Separation of Various Components from Uranium by Oxidation-Rcauction Reactions in in a Liquid KCl-LiCl/Ziric System, Report is-28:; Ames La'ooratory, (April 10, 1961)

[4] R. K. Steuncnberg, R. D.Pjerce and I. Johnson, Status of the Salt Transport Process for Fast Brceder Reactor Fuels, Symposium on Reprocessing of Nuclear Fuels, P. Chiotti,Editor, Nuclear Metallurgy, Volume 15, Conf-690ة01, pp 325-335,(August 1969)

[5] J. B. Knighton, I.Johnson and R. K. Steunenberg, Uranium and Plutonium Purification by the Salt Transport Process,ibid, pp 337-362

[6] I. Johnson,Partition of Metals bctwcen Liquid Metal Solutions and Fused Salts, Application of Fundamental Thermodynamics to Metallurgical Processes, G. R. Fitterer, Editor, Gordon and Breach, New York, pp 153-196,(1967)

[7] L. B. Pankratz, Thermodynamic Properties of Halides, Bulletin 674, U.S. Bureau of Mines, (1984)

[8] J.Fuger, V. B. Parker, W. N. Hubbard and F. L. Oetting, The Chemical Thermadynamics of Actinide Elements and Compounds, Part 8, The Actinide Halides, IAFA, Vienna, p.248,(1983)

[9] P. Chiotti and E. R. Stevens, Trans. Met. Soc. A.I.M.E.,233,198-203(1965)

[10] I. Johnson, Thermodynamics of Plutonium, Thorium and Uranium Metallic Systems, Compounds of Interest in Nuclear Reactor Technology, J. T. Waber and P. Chiotti, Ediłors, IMD Special Report No. 13, A.I.M.E, pp. 171-192(1964)

[11] P. Chiotti, The Mg-U System, Bulletin of Alloy Phase Diagrams,1,108-109(1980)

[12] L. S. Darkin, J. Am. Chem. Soc.72,2909(1959)

[i3] C. B. Alcoct and F. D. Richardson, Acta Met. 8,882(1960)

[14] I. Johnson and H. M. Feder Thermodynamics of Binary Systems of Uranium with $Z_{n}$, $C d, G a, I n, T l, S n$ and $P b$., Thermodynamics of Nuclear Materials, IAEA, Vienna, pp. 319-329(1962)

[15] J. B. Knighton and R. K. Steunenberg, Trans. Amer. Nucl. Soc.,5,460(1962) 
[16] H. Moriyama, K. Yajima, N. Nunogane, T. Ohmura, K. Moritani and J. Oishi, Jour. Nuclear Sci. and T'ech.,21,949-958(1984)

[17] L. M. Ferris, J. C. Mailen, J. J. Lawrance, F. J. Snith and E. D. Noguera, J. Inorg. Nucl. Chem.,32,2019(1970)

[18] L. J.Mullins and J. A.Leary, I \& EC Process Design and Development,4,394-400(1965)

[19] I. Johnson, The Solubility of Uranium and Plutonium in Liquid Alloys, Symposium on Reprocessing of Nuclear Fuels, P.Chiotti, Editur, Nuclear Metallurgy, Vol. 15, Coni690801, pp 547-575(August 1969)

[20] I. Johnson, Jour. Nucl. Matl.,51,163-177(1974)

[21] W.J. Walsh et al.,Engincering Studies of Salt Transport Scparations, Chem. Eng. Div., Argonne National Lab., Semi-annual report, July-Dec 1966, ANL-7325,p 26 (April 1967)

[22] L. Burris, R.K. Steunenberg and W.E.Miller, The Application of Elcctrorcfining for Recovery and Puification of Fuel Discharged from the Integral Fast Reactor,AJChE Symposium Series, No. 254, Vol. 82, pp. 135-142(1987)

[23] G.Chauvin, H.Coriou, P.Jabot, and A.Laroche, J. Nucl. Matl.11,183-192(1964)

[24] I.Johnson, M.G.Chasanov and R.M. Yonco, Trans. Miet. Soc. AIME 233, 1408-1414.(1965)

[25] I.Johnson and H.M.Feder, Trans. Met. Soc. AJME,224,468-473(1962)

[26] A.E.Martin, I.Johnson and H.M.Feder, Trans. Met. Soc. AIME,221,789-791(1961) 


\section{Legends for Figures}

Fig. 1. Comparison of Calculated and Observed ${ }^{15}$ Distribution of Uranium between Molten $\mathrm{MgCl}_{2}$ and Liquid $\mathrm{Mg}-\mathrm{Zn}$ Alloys at $1073 \mathrm{~K}$.

Fig. 2. Calculated EMF during Electrotrarenert of Uranium and Plutonium, $773 \mathrm{~K}$. Curve ABC, calculated from data in Tabi: 3. Curve DEF, calculated from data in Table 4. Segment $A B$, both anode and cathote single (liquid) phase. Segment $B C$, anode single phase, cathode two phase (liquid alioy and solid U). Segment DE, anode two phase and cathode single phase. Segment EF, both anode and cathode two phase (liquid alloy and solid U). 


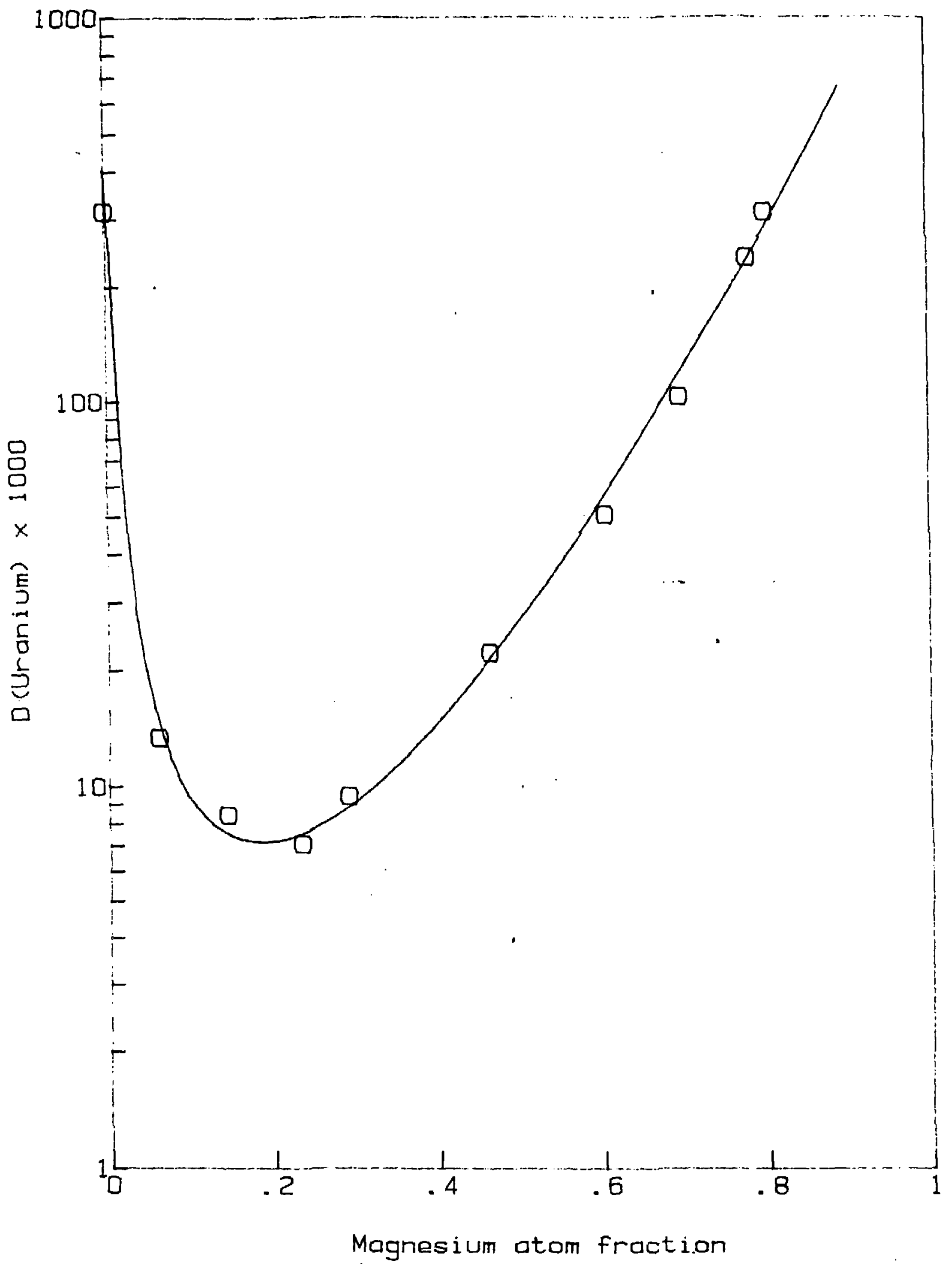




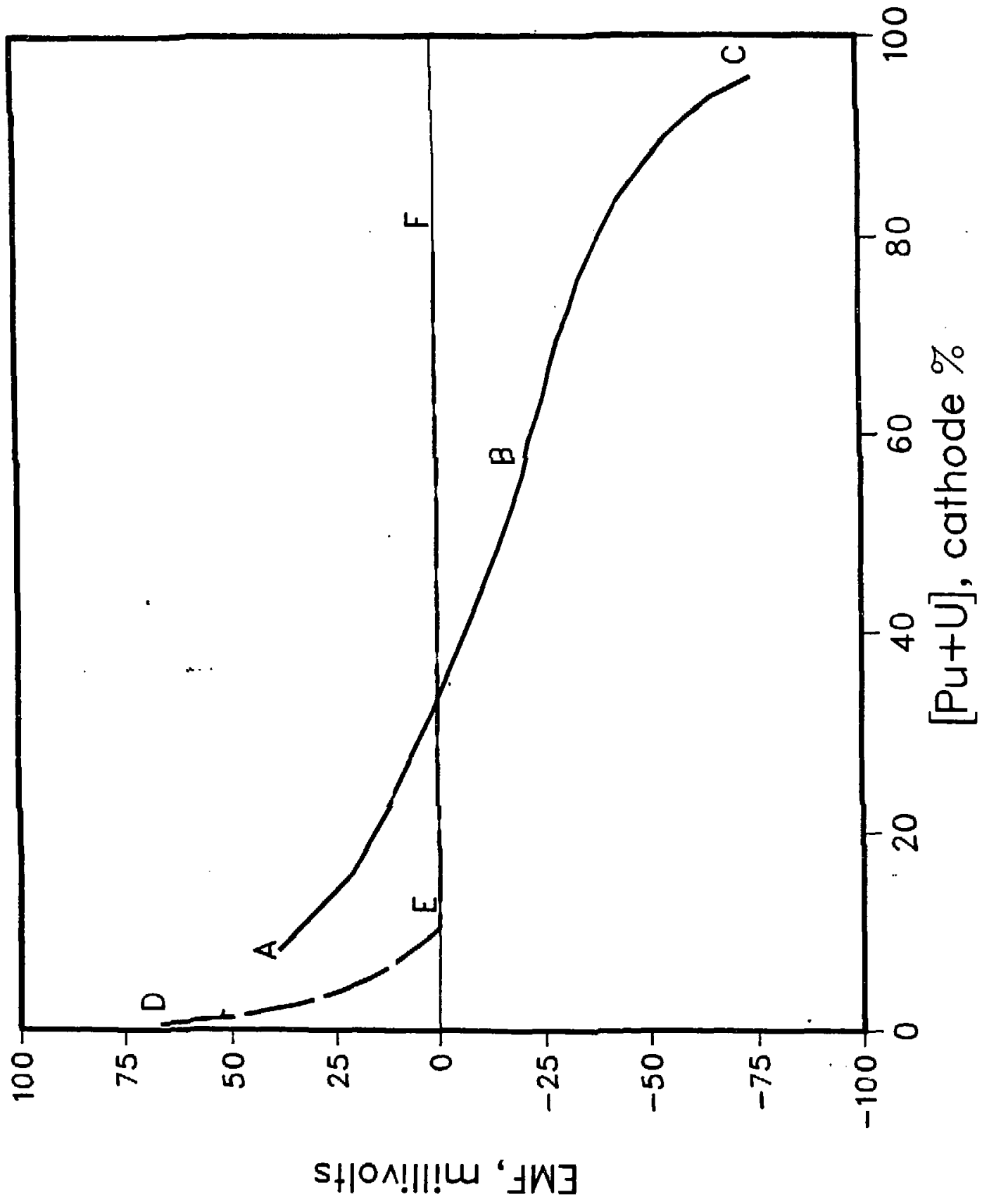

